
Kidney
Bloód Pressure
Research

Review

\title{
Diagnostic and Prognostic Utility of Neutrophil Gelatinase-Associated Lipocalin (NGAL) in Patients with Cardiovascular Diseases - Review
}

\author{
Katerina Helanova ${ }^{a} \quad$ Jindrich Spinar ${ }^{a, b} \quad$ Jiri Parenica ${ }^{a, b}$ \\ aDepartment of Cardiology, University Hospital Brno and Faculty of Medicine, Masaryk University Brno; \\ bInternational Clinical Research Center - Department of Cardiovascular Disease, University Hospital St \\ Anne's, Brno, Czech Republic
}

\section{Key Words}

NGAL • Biomarker • Cardiovascular disease $\cdot$ Prognosis $•$ Diagnosis • AKI

\begin{abstract}
NGAL (neutrophil gelatinase-associated lipocalin) is an acute phase protein, participating in antibacterial immunity. NGAL forms a complex with metalloproteinase 9 (MMP-9), thereby increasing its activity and preventing its degradation. NGAL is freely filtered through the glomerular membrane and reabsorbed by endocytosis in the proximal tubule. NGAL detected in urine is produced mainly in the distal nephron. Elevated serum and urine NGAL allows diagnosis of acute kidney injury approximately 24 hours earlier than plasma creatinine concentration. Increased levels of NGAL were detected in patients with acute myocardial infarction, heart failure or stroke and were demonstrated to be strong predictors of adverse prognosis.
\end{abstract}

Copyright $(2014$ S. Karger AG, Basel

\section{NGAL - physiological functions}

Neutrophil gelatinase-associated lipocalin (NGAL), also called lipocalin-2, is a representative of a large group of lipocalins, which are small extracellular proteins with a variety of functions. This acute phase protein is a $25 \mathrm{kDa}$ large glycosylated monomer of simple protein chains. It was originally identified as a protein isolated from specific neutrophil granules [1] and subsequently it was proved to be covalently bound with 


\section{Kidney Blood Pressure Research}

neutrophil gelatinase (an enzyme of the matrix metalloproteinase group - collagenase IV of $92 \mathrm{kDa}$, contained in neutrophils) [2]. In addition to excretion by activated neutrophils, NGAL may also be released in small concentrations by epithelial cells, kidney tubular cells, and in the case of inflammation or injury also by hepatocytes [3]. It is also present in endothelial cells and macrophages. High levels of NGAL were also documented in adipocytes potentially related to insulin resistance in obese people [4]. NGAL levels depend on gender, age and liver function and they correlate with inflammatory parameters.

NGAL is an important part of natural antibacterial immunity. Its bacteriostatic properties are determined by the attachment to bacterial siderophores, by which it prevents bacteria from acquiring iron from the surroundings [3]. Therefore, it occurs in the tissues which are normally exposed to the external environment, such as respiratory, gastrointestinal and urinary tract. During the development of kidneys, NGAL supports epithelial differentiation of mesenchymal stem cells, which results in the formation of glomeruli, proximal tubules, the loop of Henle and distal tubules [5, 6].

The expression of NGAL is greatly increased in cases of damage of epithelial cells of the kidneys, large intestine, liver and lungs. This is probably mediated by a group of transcription factors denoted as NF- $\kappa \mathrm{B}$ which are able to quickly activate epithelial cells following acute damage [7]. An important function of NGAL is the formation of a complex with matrix metalloproteinase 9 (MMP-9), which slows down the inactivation of MMP-9 by tissue inhibitors of matrix metalloproteinases (TIMP-1) and results in a longer effect of the proteolytic activity of MMP-9. Prolonged activity of MMP-9 participates in the degradation of collagen $[8,9]$. The formation of NGAL is often induced in a number of human tumours such as adenomas and inflamed epithelia of the bowel [10], adenocarcinomas of the breast [11] and urothelial carcinomas [12]. NGAL itself may then participate in the invasive behaviour of tumours. NGAL is a predictor of poor prognosis [13-15].

\section{NGAL - a biomarker of kidney injury}

Plasma NGAL is freely filtered through the glomerular membrane and almost completely reabsorbed by endocytosis in the proximal tubule. The detection of NGAL in urine is only possible when the proximal tubule has been damaged and the reabsorption is thus impaired, or when the de-novo synthesis of NGAL is markedly increased. Studies of NGAL gene expression in acute renal impairment have shown a quick and massive up-regulation of NGAL mRNA in the distal nephron, in particular in the ascending limb of Henle's loop and in the collecting duct. The resulting synthesis of the NGAL protein and its secretion in the distal nephron therefore apparently form the major part of the NGAL detected in urine. Increased expression of NGAL in the distal tubule and its rapid secretion into the lower urinary tract corresponds with its antimicrobial function and the promotion of cell growth.

In relation to the plasma level of NGAL, however, the kidneys do not appear to be its primary source. Samples of ipsilateral renal vein after unilateral ischemia during animal studies have shown that NGAL synthesised in the kidneys is not released into the bloodstream, but is present in a sample amount in the ipsilateral ureter [16]. Acute kidney injury causes increased expression of NGAL mRNA, particularly in the liver and lungs. A newly formed NGAL protein is released into the circulating blood and represents the majority of the 'NGAL system pool'. Another part of systemic NGAL comes from neutrophils and monocytes, as it is the reactant of the acute phase and during an immune reaction it is released into the systemic circulation by these cells [17]. Decreases in GFR resulting from renal impairment lead to a decrease in renal clearance of NGAL and its subsequent accumulation in the systemic circulation. The exact participation of these mechanisms in the rise of NGAL plasma levels has not yet been established. Significant information in this respect is that NGAL concentration in the blood and urine increases as quickly as two hours after renal impairment (ischaemic, nephrotoxic or septic). An increase in the concentration of NGAL thus precedes an increase in the amount of creatinine in the serum by 12 to 24 hours [18]. For example, in diagnostics 


\section{Kidney Blood Pressure Research}

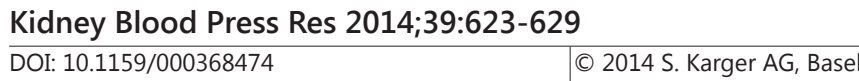

Publisnea onIIne: December 15, 2014

www.karger.com/kbr

Helanova/Spinar/Parenica: NGAL in Cardiovascular Disease

using a contrast medium in induced nephropathy, it is possible to determine NGAL levels as quickly as two hours after application of the contrast medium in the urine as well as serum (sensitivity $71 \%$, specificity 100\%) [19].

Several studies have demonstrated a correlation between NGAL levels and poor clinical outcomes, including worsening of AKI, the need for renal replacement therapy and mortality. Analysis of pooled data from 2322 critically ill patients revealed that in a group of patients without of AKI (according to conventional definition based on increased level of serum creatinine) elevated levels of NGAL identified patients with increased risk of subsequent renal replacement therapy $(0.0015 \%$ vs $2.5 \%$;odds ratio $16.4, \mathrm{p}<0.001)$ and hospital mortality ( $4.8 \%$ vs $12.4 \%$ ) [20]. In the absence of diagnostic increases in serum creatinine, NGAL so detects patients with likely subclinical AKI and increased risk of adverse outcomes [21-24].

Urinary NGAL could be a sensitive and early indicator of gentamicin nephrotoxicity. Significant changes occurred within $24 \mathrm{~h}$, before changes in serum creatinine [25].

In patients with chronic renal insufficiency, NGAL levels correlate with the severity of renal impairment, serum creatinine level, glomerular filtration (GFR), and proteinuria. Nevertheless, it must be noted that the relative increase in plasma NGAL is generally much lower than is usual in acute kidney injury [26].

NGAL as a biomarker of acute kidney injury possesses almost all the ideal characteristics of a biomarker: it is easily obtained from a blood or urine sample, it is measurable by standardised laboratory methods, it is sufficiently sensitive for early recognition of renal impairment, and its dynamic range and cut-off values are broad enough to allow stratification of risk. A disadvantage of NGAL as a biomarker of acute renal impairment is that the level of plasma NGAL may be simultaneously affected by other medical conditions such as hypertension, systemic inflammatory diseases, anaemia, ischemia or malignancy $[13,27]$.

For example, sepsis limits the diagnostic utility of NGAL in critically ill septic patients. Sepsis itself is an important inducer of blood and urinary NGAL expression (NGAL originates not only from the injured kidney, but also from leucocytes and the liver). Plasma and urinary NGAL levels are substantially higher in patients with septic AKI compared to non-septic AKI [28].

\section{NGAL and cardiovascular diseases}

In cardiovascular diseases, there may be more mechanisms causing elevated NGAL levels, and they may be active in several ways. Increased levels of NGAL were found in patients with hypertension compared to those with normal blood pressure, which were related to renal function (expressed by glomerular filtration and the level of creatinine or cystatin C), age and the duration of hypertension [27]. In a group of hypertonic patients with atherosclerosis of carotid arteries, a correlation between serum NGAL level and diastolic blood pressure (and age) was found [29].

In the case of atherosclerotic arteries, NGAL may play a part in vascular remodelling and the instability of atherosclerotic plaques. The presence of NGAL has been documented in the vascular media, both in its free form and in a complex with MMP-9. As mentioned above, the formation of a complex of NGAL and MMP-9 prevents degradation of MMP-9 and reinforces its proteolytic activity which can take part in the formation of an unstable atherosclerotic plaque. This complex is located in atherosclerotic plaques and its increased concentration has been detected in plaques with intramural haematoma and central necrosis [30-33]. NGAL serum levels are significantly higher in patients with angiographically-confirmed CAD compared to controls with normal arteries [34,35].

Elevated levels of serum NGAL have been found in patients after an acute cerebrovascular accident (stroke, TIA) and lasted up to one year [36].

Increased NGAL expression also occurs in patients suffering from acute myocardial infarction. It may be considered as an active mediator of post-ischaemic inflammation and 


\section{Kidney Blood Pressure Research}

Table 1. Comparison of actual levels of NGAL of patients with different cardiovascular disease (hypertension, stroke/transient ischemic attack, myocardial infarction and acute heart failure)

\begin{tabular}{|c|c|c|c|}
\hline Malyszko [27] & Hypertensives and CAD & Normotensive and CAD & Healthy volunteers \\
\hline NGAL ( $\mu \mathrm{g} / \mathrm{L})$ & $115.15 \pm 33.34$ & $88.89 \pm 18.65$ & $75.68 \pm 22.31$ \\
\hline Elneihourm [36] & Stroke & TIA & Healthy volunteers \\
\hline NGAL $(\mu \mathrm{g} / \mathrm{L})$ & $122(67-625)$ & $110(69-351)$ & $97(37-212)$ \\
\hline Lindberg [37] & STEMI & \multicolumn{2}{|c|}{ Cutoff for high risk patients ( 75 th percentile) } \\
\hline NGAL $(\mu \mathrm{g} / \mathrm{L})$ & $134.2(44.9-400.6)$ & \multicolumn{2}{|c|}{170.1} \\
\hline Palazzuoli [39] & AHF & AHF and preserved RF & AHF and impaired RF \\
\hline NGAL $(\mu \mathrm{g} / \mathrm{L})$ & $184 \pm 171$ & $130 \pm 80$ & $241 \pm 218$ \\
\hline
\end{tabular}

the remodelling reaction. The level of NGAL is increased in the necrotic zone of the infarction and in the surrounding healthy tissue. The serum level of NGAL increases simultaneously, as compared with healthy individuals. It has been established that significantly higher NGAL levels following MI predict an adverse outcome. Lindberg et al. demonstrated in patients with STEMI that high NGAL upon admission (> 75th percentile) independently predicted all-cause mortality (hazard ratio: 2.00 ; $95 \% \mathrm{CI}: 1.16$ to $3.44 ; \mathrm{p}=0.01$ ) and major adverse cardiac events (MACE) defined as cardiovascular mortality and admission due to recurrent myocardial infarction or heart failure (hazard ratio: $1.51 ; 95 \% \mathrm{CI}: 1.00$ to $2.30 ; \mathrm{p}=0.05$ ) [37]. A comparison of actual levels of NGAL in patients with different cardiovascular diseases is shown in a Table 1.

Apparently, NGAL plays a role in the pathogenesis of heart failure. The activation of neutrophils and the subsequent release of NGAL participate in the development of inflammatory reactions during the course of heart failure. Remodelling of the left ventricle, which leads to the development and the progression of heart failure, is a very complex process, which not only involves changes in cardiomyocytes, but also changes in the extracellular matrix. Activated metalloproteinases are important mediators in this process. In their study, Yndestad et al. demonstrated that patients with heart failure following MI, as well as patients with chronic heart failure of any other aetiology, had elevated serum levels of NGAL that significantly correlated with their clinical and neurohormonal deterioration. In a rat model of post-MI heart failure, NGAL/lipocalin-2 gene expression was increased also in the non-ischaemic part of the left ventricle primarily located to cardiomyocytes [38].

\section{Conclusion}

NGAL as diagnostic marker: Elevated NGAL level as an early blood-based marker of AKI is detectable within 2-12 hours after an ischemic/toxic insult in patients with cardiovascular diseases. Although NGAL in urine and in serum have a somewhat different origin, both are useful for early diagnosis of AKI. A widespread use of NGAL in a clinical practice is limited by absence of prospective studies demonstrating that early diagnosis of AKI using NGAL compared with creatinine leads to improved prognosis of patients and reduced treatments costs (evidence-based laboratory medicine).

NGAL as prognostic marker: Elevated levels of NGAL have been detected in patients with acute myocardial infarction, heart failure and after a cerebrovascular attack and prognostic significance of increased NGAL was clearly demonstrated. A general clinical utility for an identification of high risk patients that would allow target increased medical care and efficient use of resources just for their care remains to be shown. 


\section{Kidney \\ Blood Pressure Research}

Helanova/Spinar/Parenica: NGAL in Cardiovascular Disease

\section{Disclosure Statement}

The authors disclose no relevant industry or other relationships.

\section{Acknowledgements}

Financial support for this study was provided by MH CZ - DRO (FNBr, 65269705) and by Grant MUNI/A/1012/2013.

\section{References}

1 Xu SY, Carlson M, Engström A, Garcia R, Peterson CG, Venge P: Purification and Characterization of a Human Neutrophil Lipocalin (HNL) from the Secondary Granules of Human Neutrophils. Scand J Clin Lab Invest 1994;54:365-376.

-2 Kjeldsen L, Johnsen AH, Sengeløv H, Borregaard N: Isolation and Primary Structure of NGAL, a Novel Protein Associated with Human Neutrophil Gelatinase. J Biol Chem 1993;268:10425-10432.

- 3 Flo TH, Smith KD, Sato S, Rodriguez DJ, Holmes MA, Strong RK, Akira S, Aderem A: Lipocalin 2 Mediates an Innate Immune Response to Bacterial Infection by Sequestrating Iron. Nature 2004;432:917-921.

-4 Yan Q-W, Yang Q, Mody N, Graham TE, Hsu C-H, Xu Z, Houstis NE, Kahn BB, Rosen ED: The Adipokine Lipocalin 2 Is Regulated by Obesity and Promotes Insulin Resistance. Diabetes 2007;56:2533-2540.

5 Yang J, Blum A, Novak T, Levinson R, Lai E, Barasch J: An Epithelial Precursor Is Regulated by the Ureteric Bud and by the Renal Stroma. Dev Biol 2002;246:296-310.

6 Yang J, Goetz D, Li JY, Wang W, Mori K, Setlik D, Du T, Erdjument-Bromage H, Tempst P, Strong R, Barasch J. An Iron Delivery Pathway Mediated by a Lipocalin. Mol Cell 2002;10:1045-1056.

-7 Meldrum KK, Hile K, Meldrum DR, Crone JA, Gearhart JP, Burnett AL: Simulated Ischemia Induces Renal Tubular Cell Apoptosis through a Nuclear Factor-kappaB Dependent Mechanism. J Urol 2002;168:248-252.

-8 Gupta K, Shukla M, Cowland JB, Malemud CJ, Haqqi TM: Neutrophil Gelatinase-Associated Lipocalin Is Expressed in Osteoarthritis and Forms a Complex with Matrix Metalloproteinase 9. Arthritis Rheum 2007;56:3326-3335.

-9 Yan L, Borregaard N, Kjeldsen L, Moses MA: The High Molecular Weight Urinary Matrix Metalloproteinase (MMP) Activity Is a Complex of Gelatinase B/MMP-9 and Neutrophil Gelatinase-Associated Lipocalin (NGAL). Modulation of MMP-9 Activity by NGAL. J Biol Chem 2001;276:37258-37265.

10 Nielsen BS, Borregaard N, Bundgaard JR, Timshel S, Sehested M, Kjeldsen L: Induction of NGAL Synthesis in Epithelial Cells of Human Colorectal Neoplasia and Inflammatory Bowel Diseases. Gut 1996;38:414-420.

11 Stoesz SP, Friedl A, Haag JD, Lindstrom MJ, Clark GM, Gould MN: Heterogeneous Expression of the Lipocalin NGAL in Primary Breast Cancers. Int J Cancer 1998;79:565-572.

12 Monier F, Surla A, Guillot M, Morel F: Gelatinase Isoforms in Urine from Bladder Cancer Patients. Clin Chim Acta 2000;299:11-23.

13 Devarajan P: The Promise of Biomarkers for Personalized Renal Cancer Care. Kidney Int 2010;77:755-757.

-14 Tong Z, Kunnumakkara AB, Wang H, Matsuo Y, Diagaradjane P, Harikumar KB, Ramachandran V, Sung B, Chakraborty A, Bresalier RS, Logsdon C, Aggarwal BB, Krishnan S, Guha S: Neutrophil GelatinaseAssociated Lipocalin: A Novel Suppressor of Invasion and Angiogenesis in Pancreatic Cancer. Cancer Res 2008;68:6100-6108.

15 Bauer M, Eickhoff JC, Gould MN, Mundhenke C, Maass N, Friedl A: Neutrophil Gelatinase-Associated Lipocalin (NGAL) Is a Predictor of Poor Prognosis in Human Primary Breast Cancer. Breast Cancer Res Treat 2008;108:389-397.

16 Schmidt-Ott KM, Mori K, Li JY, Kalandadze A, Cohen DJ, Devarajan P, Barasch J: Dual Action of Neutrophil Gelatinase-Associated Lipocalin. J Am Soc Nephrol 2007;18:407-413.

17 Grigoryev DN, Liu M, Hassoun HT, Cheadle C, Barnes KC, Rabb H: The Local and Systemic Inflammatory Transcriptome after Acute Kidney Injury. J Am Soc Nephrol 2008;19:547-558. 


\section{Kidney \\ Blood Pressure Research}

Kidney Blood Press Res 2014;39:623-629

DOI: 10.1159/000368474

Published onIIne: December 15, 2014

(C) 2014 S. Karger AG, Basel

www.karger.com/kbr

Helanova/Spinar/Parenica: NGAL in Cardiovascular Disease

18 Mishra J, Dent C, Tarabishi R, Mitsnefes MM, Ma Q, Kelly C, Ruff SM, Zahedi K, Shao M, Bean J, Mori K, Barasch J, Devarajan P: Neutrophil Gelatinase-Associated Lipocalin (NGAL) as a Biomarker for Acute Renal Injury after Cardiac Surgery. Lancet 2005;365:1231-1238.

19 Hirsch R, Dent C, Pfriem H, Allen J, Beekman RH, Ma Q, Dastrala S, Bennett M, Mitsnefes M, Devarajan P: NGAL Is an Early Predictive Biomarker of Contrast-Induced Nephropathy in Children. Pediatr Nephrol Berl Ger 2007;22:2089-2095.

-20 Haase M, Devarajan P, Haase-Fielitz A, Bellomo R, Cruz DN, Wagener G, Krawczeski CD, Koyner JL, Murray P, Zappitelli M, Goldstein SL, Makris K, Ronco C, Martensson J, Martling C-R, Venge P, Siew E, Ware LB, Ikizler TA, Mertens PR: The Outcome of Neutrophil Gelatinase-Associated Lipocalin-Positive Subclinical Acute Kidney Injury: A Multicenter Pooled Analysis of Prospective Studies. J Am Coll Cardiol 2011;57:1752-1761.

21 Nickolas TL, Schmidt-Ott KM, Canetta P, Forster C, Singer E, Sise M, Elger A, Maarouf O, Sola-Del Valle DA, O’Rourke M, Sherman E, Lee P, Geara A, Imus P, Guddati A, Polland A, Rahman W, Elitok S, Malik N, Giglio J, El-Sayegh S, Devarajan P, Hebbar S, Saggi SJ, Hahn B, Kettritz R, Luft FC, Barasch J: Diagnostic and Prognostic Stratification in the Emergency Department Using Urinary Biomarkers of Nephron Damage: A Multicenter Prospective Cohort Study. J Am Coll Cardiol 2012;59:246-255.

-22 Singer E, Elger A, Elitok S, Kettritz R, Nickolas TL, Barasch J, Luft FC, Schmidt-Ott KM: Urinary Neutrophil Gelatinase-Associated Lipocalin Distinguishes Pre-Renal from Intrinsic Renal Failure and Predicts Outcomes. Kidney Int 2011;80:405-414.

23 Hall IE, Coca SG, Perazella MA, Eko UU, Luciano RL, Peter PR, Han WK, Parikh CR: Risk of Poor Outcomes with Novel and Traditional Biomarkers at Clinical AKI Diagnosis. Clin J Am Soc Nephrol 2011;6:2740-2749.

24 Chen T-H, Chang C-H, Lin C-Y, Jenq C-C, Chang M-Y, Tian Y-C, Hung C-C, Fang J-T, Yang C-W, Wen M-S, Lin F-C, Chen Y-C: Acute Kidney Injury Biomarkers for Patients in a Coronary Care Unit: A Prospective Cohort Study. PloS One 2012;7:e32328.

-25 Hoffmann D, Fuchs TC, Henzler T, Matheis KA, Herget T, Dekant W, Hewitt P, Mally A: Evaluation of a Urinary Kidney Biomarker Panel in Rat Models of Acute and Subchronic Nephrotoxicity. Toxicology 2010;277:49-58.

26 Bolignano D, Lacquaniti A, Coppolino G, Campo S, Arena A, Buemi M: Neutrophil Gelatinase-Associated Lipocalin Reflects the Severity of Renal Impairment in Subjects Affected by Chronic Kidney Disease. Kidney Blood Press Res 2008;31:255-258.

27 Malyszko J, Bachorzewska-Gajewska H, Malyszko JS, Pawlak K, Dobrzycki S: Serum Neutrophil GelatinaseAssociated Lipocalin as a Marker of Renal Function in Hypertensive and Normotensive Patients with Coronary Artery Disease. Nephrol Carlton Vic 2008;13:153-156.

-28 Bagshaw SM, Bennett M, Haase M, Haase-Fielitz A, Egi M, Morimatsu H, D’amico G, Goldsmith D, Devarajan P, Bellomo R: Plasma and Urine Neutrophil Gelatinase-Associated Lipocalin in Septic versus Non-Septic Acute Kidney Injury in Critical Illness. Intensive Care Med 2010;36:452-461.

-29 Elneihoum AM, Falke P, Hedblad B, Lindgärde F, Ohlsson K: Leukocyte Activation in Atherosclerosis: Correlation with Risk Factors. Atherosclerosis 1997;131:79-84.

-30 Hemdahl A-L, Gabrielsen A, Zhu C, Eriksson P, Hedin U, Kastrup J, Thorén P, Hansson GK: Expression of Neutrophil Gelatinase-Associated Lipocalin in Atherosclerosis and Myocardial Infarction. Arterioscler Thromb Vasc Biol 2006;26:136-142.

-31 Leclercq A, Houard X, Philippe M, Ollivier V, Sebbag U, Meilhac O, Michel J-B: Involvement of Intraplaque Hemorrhage in Atherothrombosis Evolution via Neutrophil Protease Enrichment. J Leukoc Biol 2007;82:1420-1429.

-32 Te Boekhorst BC, Bovens SM, Hellings WE, van der Kraak PH, van de Kolk KW, Vink A, Moll FL, van Oosterhout MF, de Vries JP, Doevendans PA, Goumans M-J, de Kleijn DP, van Echteld CJ, Pasterkamp G, Sluijter JP: Molecular MRI of Murine Atherosclerotic Plaque Targeting NGAL: A Protein Associated with Unstable Human Plaque Characteristics. Cardiovasc Res 2011;89:680-688.

-33 Kalousek I, Röselová P, Otevrelová P: NGAL--neutrophil gelatinase associated lipocalin in biochemistry, physiology and clinical praxis. Casopis Lekaru Ceskych 2006;145:373-376.

-34 Choi KM, Lee JS, Kim EJ, Baik SH, Seo HS, Choi DS, Oh DJ, Park CG: Implication of Lipocalin-2 and Visfatin Levels in Patients with Coronary Heart Disease. Eur J Endocrinol 2008;158:203-207.

-35 Zografos T, Haliassos A, Korovesis S, Giazitzoglou E, Voridis E, Katritsis D: Association of Neutrophil Gelatinase-Associated Lipocalin with the Severity of Coronary Artery Disease. Am J Cardiol 2009;104:917920. 


\section{Kidney \\ Blood Pressure Research}

Helanova/Spinar/Parenica: NGAL in Cardiovascular Disease

-36 Elneihoum AM, Falke P, Axelsson L, Lundberg E, Lindgärde F, Ohlsson K: Leukocyte Activation Detected by Increased Plasma Levels of Inflammatory Mediators in Patients with Ischemic Cerebrovascular Diseases. Stroke J Cereb Circ 1996;27:1734-1738.

37 Lindberg S, Pedersen SH, Mogelvang R, Jensen JS, Flyvbjerg A, Galatius S, Magnusson NE: Prognostic Utility of Neutrophil Gelatinase-Associated Lipocalin in Predicting Mortality and Cardiovascular Events in Patients with ST-Segment Elevation Myocardial Infarction Treated with Primary Percutaneous Coronary Intervention. J Am Coll Cardiol 2012;60:339-345.

-38 Yndestad A, Landrø L, Ueland T, Dahl CP, Flo TH, Vinge LE, Espevik T, Frøland SS, Husberg C, Christensen G, Dickstein K, Kjekshus J, Øie E, Gullestad L, Aukrust P: Increased Systemic and Myocardial Expression of Neutrophil Gelatinase-Associated Lipocalin in Clinical and Experimental Heart Failure. Eur Heart J 2009;30:1229-1236.

39 Palazzuoli A, Ruocco G, Beltrami M, Franci B, Pellegrini M, Lucani B, Nuti R, Ronco C: Admission Plasma Neutrophil Gelatinase Associated Lipocalin (NGAL) Predicts Worsening Renal Function during Hospitalization and Post Discharge Outcome in Patients with Acute Heart Failure. Acute Card Care 2014;16:93-101. 